\title{
DELIVERING SMOKING CESSATION INFORMATION IN THE WORKPLACE USING QUIT ONLINE
}

\section{Sue Hailstone}

NSW Public Health Officer Training Program NSW Department of Health

\section{Amy Wyndham and Elayne Mitchell}

Centre for Chronic Disease Prevention and

Health Advancement

NSW Department of Health

The Tobacco and Health Branch and Online Service Development at the NSW Department of Health have developed a web-based smoking cessation tool, Quit Online, for the use of NSW Health employees. This article introduces Quit Online, describes its main features and discusses the evidence supporting the electronic delivery of smoking cessation information.

\section{BACKGROUND}

NSW Health is the largest health service in the southern hemisphere, with approximately 100000 employees. ${ }^{1}$ In 2005 it implemented a Smoke Free Workplace Policy. ${ }^{2}$
There is evidence that providing assistance to smokers who wish to quit doubles their chance of success, compared to those who attempt to quit on their own. ${ }^{3}$ One strategy of the Smoke Free Workplace Policy is to provide assistance to all NSW Health employees who wish to quit smoking. Quit Online is an example of an initiative that provides smoking cessation support to employees via the NSW Health intranet.

Applying routinely collected data for smoking to the NSW Health employee data suggests that there are approximately 22000 current smokers, $22 \%$ of the workforce. ${ }^{4}$ Of these, 7333 (33\%) wish to quit in the next 6 months and an additional $3080(14 \%)$ wish to quit in the next 30 days.

A pilot version of Quit Online was tested with NSW Health employees in 2 area health services and at the Department of Health central office from November 2003. A 4-month technical trial was chosen to accommodate the 3-month smoking relapse curve that has been described in smoking

\section{FIGURE 1}

\section{QUIT ONLINE HOMEPAGE}

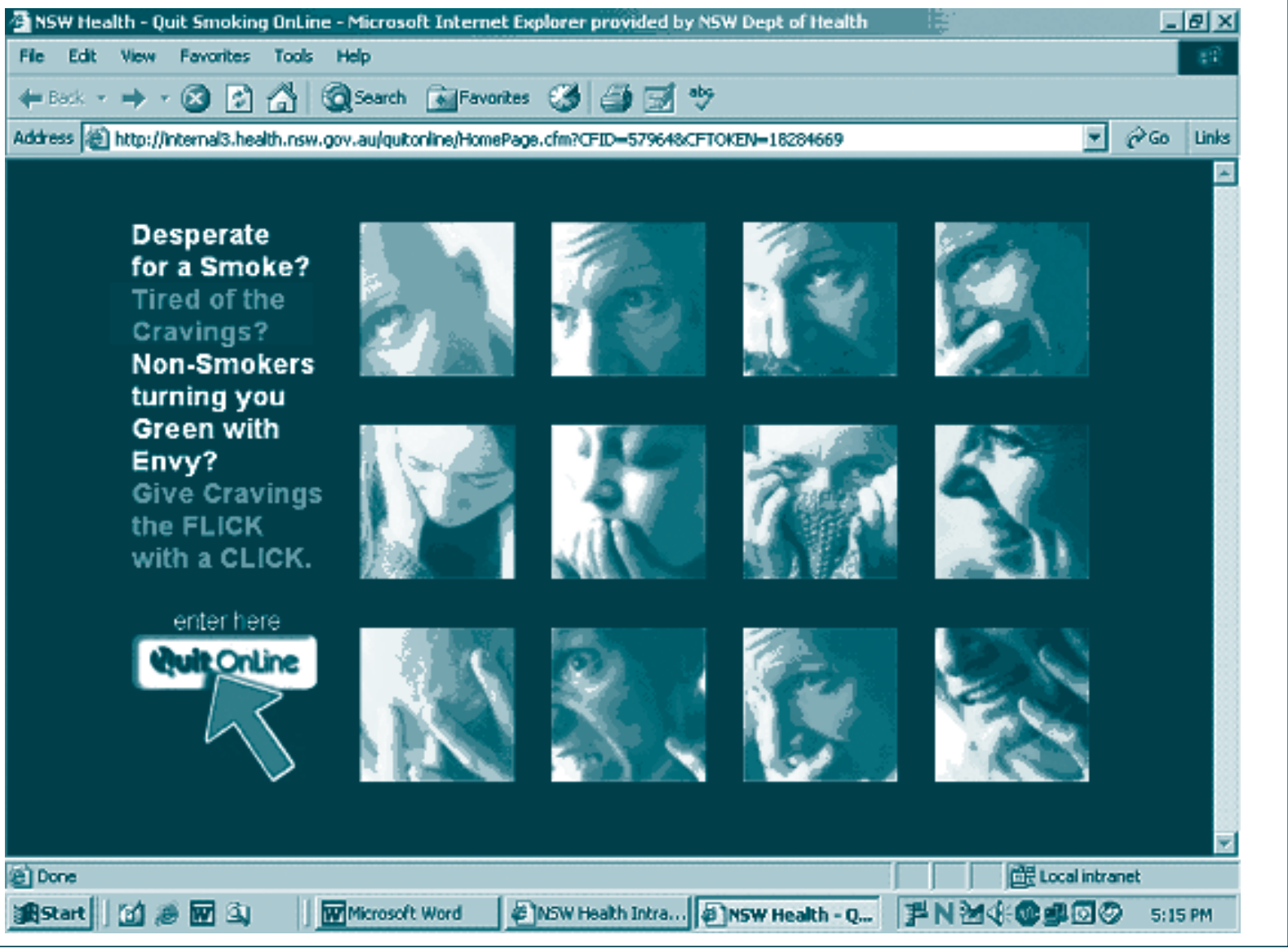


cessation literature ${ }^{5}$ and allowed for a month's delay in employees registering for the service. Following feedback and revision, Quit Online was launched on World No Tobacco Day, 31 May 2004 (Figure 1).

\section{WEBSITE DESCRIPTION}

The Quit Online website has 2 parts. The first provides general information about quitting smoking and the second provides information personalised to the user.

\section{Part 1}

The general quit smoking information available includes:

- fact sheets

- Quit Stories, footage from the NSW Health employee quit smoking video

- Quit Stories testimonials

- NSW Quitline, contact information for the telephone counselling service

- Quit Kit registration

- Quit because you can booklet

- bulletin board

- dependence calculator.
Users can access these features without registration. Navigation is easy as users click on the tabs across the top of the page and select information from drop-down menus. For example, Figure 2 illustrates the nicotine dependence calculator, which is based on the 6-item Fagerstrom test for nicotine dependence. ${ }^{6} \mathrm{~A}$ score out of 10 identifies a low, medium or high level of dependence. The score is graphically represented along the length of a burning cigarette. Additional tailored quitting information is provided, based on the level of nicotine dependence. Fourteen fact sheets provide information about tobacco and health (see Box 1). A bulletin board moderated by staff of the Tobacco and Health Branch is available for users to post questions or make comments about their quit experiences.

\section{Part 2}

The personalised quit smoking information provided includes the 'My Quit Counsellor' questionnaire and optional email and/or short messaging system (SMS) support.

The 'My Quit Counsellor' questionnaire contains 20 smoking-related questions on level of nicotine

\section{FIGURE 2}

\section{QUIT ONLINE DEPENDENCE CALCULATOR}

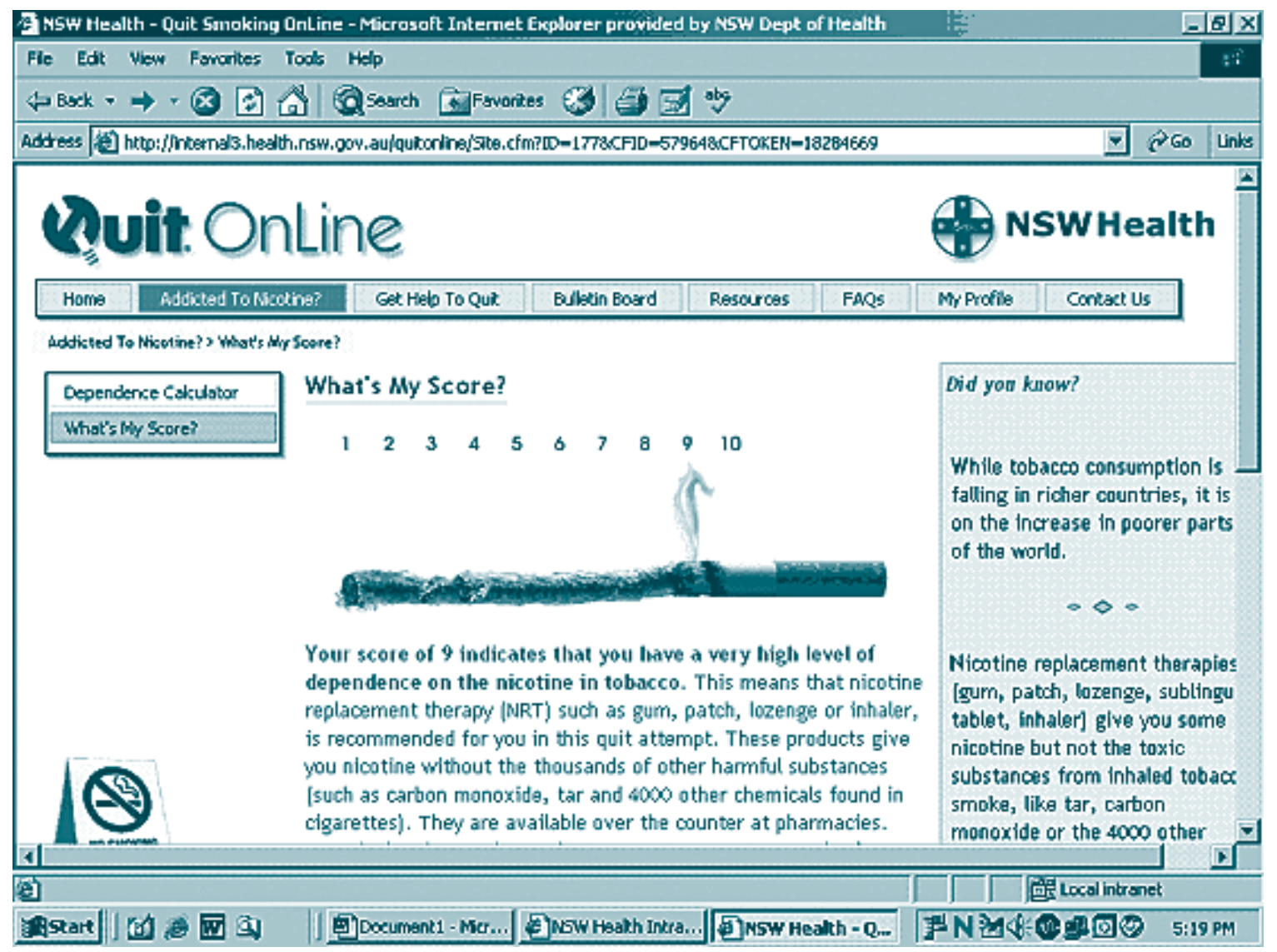


dependence, motivation for quitting, smoking history, use of pharmacotherapy and nominated quit date. Seven background questions include age group, sex and occupational grouping. After completing the questionnaire the user enters a username and selects a password, and approximately 2 pages of personalised quitting information are delivered in a matter of seconds. The information provided is both timely and tailored to personal characteristics, but is nonetheless an intervention at a single point in time.

As an adjunct to the tailored quitting information, users may subscribe to email and/or SMS support based around the 3 -month smoking cessation relapse curve. ${ }^{5}$ The majority of the automated generic messages are scheduled around the quit date. All emails have the Quit Online uniform resource locator (URL) embedded in the message, enabling users to return to the Quit Online homepage in one click.

Three messages are scheduled in the 2 weeks before quitting. For example, messages sent in the 2 weeks before quitting advise users that they may wish to purchase nicotine replacement therapies such as patches, gum, lozenges or an inhaler or see a doctor to assess whether the medication bupropion is appropriate for them. If a prescription for bupropion is obtained, the user starts taking the medication a week before quit day.

Seven messages are scheduled during the quit attempt. Emails sent on days 7, 14, 28 and 90 of the quit attempt request users to reply to Quit Online and advise whether they have remained a non-smoker. If a user has returned to smoking, a message containing relapse information is sent and remaining messages are cancelled. This capacity within the website acknowledges that several quit attempts may be required before the user achieves long-term cessation..$^{5,7}$ Registration in this part of the website enables users to update their profile at their convenience, including the nomination of a new quit date if they have returned to smoking.

\section{ENSURING EQUITY OF ACCESS}

The variety of work undertaken by NSW Health employees means that not all employees have consistent access to a computer and the intranet in the workplace. To facilitate easier access to the personalised quitting information of the website, users first register using the intranet and all subsequent access can be via the internet. This flexibility enables users to access their personalised information during and outside working hours from a range of locations. Quit Online is not currently available to the general public via the internet. However, some of the general quitting information available in part 1 of the website, including the fact sheets, the Quit because you can booklet and Quitline contact information, can be accessed by the general public through the NSW Health internet website.

\section{BOX 1}

\section{FACT SHEETS AVAILABLE AT QUIT ONLINE}

Health effects of smoking

Smoking and pregnancy

Cardiovascular disease and smoking

Nicotine and other poisons

Light cigarettes

Benefits of quitting smoking

Getting ready to quit

Quitting smoking - the first few days

Nicotine dependence and withdrawal

Remaining a non-smoker

Products to help you quit smoking

Car and home smoke-free zone

Supporting someone to quit

So you've returned to smoking

\section{EVIDENCE SUPPORTING QUIT ONLINE}

\section{Personalised quitting information}

Treatments are more effective if the needs of clients are matched to the treatment. ${ }^{9}$ Clients complete a baseline questionnaire about personal characteristics so that computer programs can provide individualised feedback. Computer-generated individualised feedback is known as an 'expert system', and these systems have been evaluated in large smoking cessation studies since the 1990s. ${ }^{9-16}$ More recently, meta-analysis has demonstrated the effectiveness of personalised computer-generated materials for smoking cessation against generic quitting materials. ${ }^{17}$

Tailored smoking cessation materials have also been shown to be effective for a range of smokers, including smokers with a low readiness to change, ${ }^{18}$ smokers with low-level nicotine dependence ${ }^{19}$ and smokers in general. ${ }^{20}$ The effectiveness of tailored materials lies in their brevity and focus. ${ }^{21}$

Using nicotine replacement therapy approximately doubles the likelihood of quitting successfully. ${ }^{22}$ Combining nicotine therapy (a pharmacological approach) with tailored self-help materials (a behavioural approach) has been recommended, ${ }^{17,23}$ and the randomised control trials have demonstrated the effectiveness of combining nicotine therapy with tailored quitting information. ${ }^{20,21}$ Accordingly, messages such as 'using nicotine replacement therapy is a smart move' and general advice on the effective use of therapy were included in Quit Online's fact sheets, in personalised quitting information and in email and SMS messages to highlight the benefits of combining the 2 modes of treatment.

Computer-based smoking cessation programs have now migrated to the web. This overcomes problems observed 
in similar projects when participants experienced delays between when they contacted a quit smoking telephone counselling service about their smoking behaviour and when they received their personalised quitting advice by surface mail. Not only do web-based expert systems deliver timely and tailored information, but the low cost of delivery allows for a greater population health benefit due to wide scale and effective distribution. ${ }^{24}$

\section{Email and SMS support}

The scheduling of email and SMS messages is consistent with evidence indicating a dose-response relationship: multiple contacts result in higher abstinence rates than a single contact. ${ }^{25}$ For example, 3 messages are sent in the first week of quitting, which is the peak period for selfreported withdrawal symptoms. ${ }^{5}$ The relapse-sensitive scheduling of messages takes into account that the probability of relapse is greater in the initial stages of quitting than later on. ${ }^{25}$ In a recent study, the scheduling of timed educational messages more than doubled the odds for quitting at 30 days as the intervention prompted smokers to plan quit attempts and undertake them more frequently. ${ }^{24}$

\section{EVALUATION OF USER CHARACTERISTICS}

One aim of the Quit Online technical trial was to identify characteristics of the first users of a workplace electronic smoking cessation tool. De-identified data from 43 'My Quit Counsellor' questionnaires were analysed. The process evaluation demonstrated that 67 per cent of users were women and 60 per cent of users were aged 30 to 49 years. Sixty-two per cent of users had previously quit for 3 months or less, and women were more likely to report low or very low levels of nicotine dependence than men (40 per cent vs. 7 per cent). A majority of users had their own computer at work (60 per cent) and more users subscribed to email support (77 per cent) than to SMS support (42 per cent).

The evaluation of personal characteristics was conducted with the initial users of the website during the 4-month technical trial. At this time, NSW Health was comprised of 21 units (17 area health services, Corrections Health, the Children's Hospital at Westmead, the Ambulance Service, and the Institute for Clinical Excellence). Participants in the trial were largely drawn from 2 area health services which employ smaller numbers of staff. A small number of respondents were also from the Department of Health central office. There was little promotion of Quit Online before the technical trial, but there were 1483 visits to the website by 1130 unique users.

\section{CONCLUSION}

NSW Health employees responded positively to Quit Online. The service uses immediate communication tools including email, SMS and the internet to support employees who wish to quit smoking. Quit Online also combines a range of evidence-based smoking cessation strategies into one product: tailored self-help materials, technologies for immediate communication, and advice on the use of nicotine replacement therapy and the Quitline. An evaluation of user characteristics suggested that the current format was suitable for use in the workplace. Key informant interviews and focus group meetings are proposed with NSW Health staff from all area health services in the latter half of 2005 and will assist in determining future directions for the project. Quit Online may then become available to other government departments and to the general public.

\section{ACKNOWLEDGMENTS}

The authors would like to thank Richard Shepherd and Ed Kazic, Online Service Development, Communications Branch, NSW Department of Health, for their assistance in developing Quit Online.

For more information about Quit Online contact Amy Wyndham at the Centre for Chronic Disease Prevention and Health Advancement, phone (02) 9391 9788, email awynd@doh.health.nsw.gov.au.

Some Quit Online resources are also available to the general public: quit smoking fact sheets, NSW Quitline contact information and the Quit because you can booklet. The resources are available at www.health.nsw.gov.au/public-health/healthpromotion/tobacco/quitting/index.html:

The Quitline 131848 is a free confidential telephone service to help smokers quit smoking. The Quitline 131848 can also provide assistance to the family and friends of smokers and others requesting information about smoking. An interpreter service is available for those who are not fluent in English.

Smokers can contact the Quitline 24 hours a day, seven days a week, every single day of the year to receive a free Quit Kit.

\section{REFERENCES}

1. NSW Department of Health. Annual report 03/04. Sydney: NSW Department of Health, 2004.

2. NSW Department of Health. NSW tobacco action plan 20012004. Sydney: NSW Department of Health, 2001.

3. Zhu S, Melcer T, Sun J, Rosbrook B, Pierce JP. Smoking cessation with and without assistance: a population-based analysis. Am J Prev Med 2000, 18: 305-311. 
4. Population Health Division. The health of the people of New South Wales: report of the Chief Health Officer, 2004. Sydney: NSW Department of Health, 2004.

5. Hughes JR, Keely J, Naud S. Shape of the relapse curve and long-term abstinence among untreated smokers. Addiction 2004; 99: 29-38.

6. Fagerström KO, Heatherton TF, Kozlowski LT. Nicotine addiction and its assessment. Ear Nose Throat J 1990; 69: 763-765.

7. Lindstrom M, Isacsson SO, Malmö Shoulder-Neck Study Group. Smoking cessation among daily smokers aged 45-69 years: a longitudinal study in Malmö, Sweden. Addiction 2002; 97: 205-215.

8. West R, McEwen A, Bolling K, Owen L. Smoking cessation and smoking patterns in the general population: a 1-year follow-up. Addiction 2001; 96: 891-900.

9. Velicer WF, Prochaska JO, Bellis JM, DiClemente CC, Rossi JS, Fava JL, Steiger JH. An expert system intervention for smoking cessation. Addict Behav 1993; 18: 269-290.

10. Borland R, Balmford J, Segan C, Livingston P, Owen N. The effectiveness of personalized smoking cessation strategies for callers to a Quitline service. Addiction 2003; 98: 837846.

11. Borland R, Balmford J, Hunt D. The effectiveness of personally tailored computer-generated advice letters for smoking cessation. Addiction 2004; 99: 369-377.

12. Etter JF, Perneger TV. Effectiveness of a computer-tailored smoking cessation program: a randomized trial. Arch Intern Med 2001; 161: 2596-2601.

13. Prochaska JO, Velicer WF, Fava JL, Rossi JS, Tsoh JY. Evaluating a population-based recruitment approach and a stage-based expert system intervention for smoking cessation. Addict Behav 2001; 26: 583-602.

14. Prochaska JO, Velicer WF, Fava JL, Ruggiero L, Laforge RG, Rossi JS, Johnson SS, Lee PA. Counselor and stimulus control enhancements of a stage-matched expert system intervention for smoking in a managed care setting. Prev Med 2001; 32: 23-32.

15. Curry SJ, McBride C, Grothaus LC, Louie D, Wagner EH. A randomized trial of self-help materials, personalized feedback, and telephone counseling with nonvolunteer smokers. $J$ Consult Clin Psychol 1995; 63: 1005-1014.

16. Prochaska JO, DiClemente CC, Velicer WF, Rossi JS. Standardized, individualized, interactive, and personalized self-help programs for smoking cessation. Health Psychol 1993; 12: 399-405.

17. Lancaster T, Stead LF. Self-help interventions for smoking cessation. Cochrane Database Syst Rev 2002; (3): CD001292.

18. Dijkstra A, De Vries H, Roijackers J. Targeting smokers with low readiness to change with tailored and nontailored selfhelp materials. Prev Med 1999; 28: 203-211.

19. Strecher VJ, Kreuter M, den Boer DJ, Kobrin S, Hospers HJ, Skinner CS. The effects of computer-tailored smoking cessation messages in family practice settings. J Fam Pract 1994; 39: 262-270.

20. Shiffman S, Paty JA, Rohay JM, Di Marino ME, Gitchell J. The efficacy of computer-tailored smoking cessation material as a supplement to nicotine polacrilex gum therapy. Arch Intern Med 2000; 160: 1675-1681.

21. Shiffman S, Paty JA, Rohay JM, Di Marino ME, Gitchell JG. The efficacy of computer-tailored smoking cessation material as a supplement to nicotine patch therapy. Drug Alcohol Depend 2001; 64: 35-46.

22. Silagy C, Lancaster T, Stead L, Mant D, Fowler G. Nicotine replacement therapy for smoking cessation. Cochrane Database Syst Rev 2001; (3): CD000146.

23. Fiore MC, Bailey WC, Cohen SJ, Dorfman SF, Goldstein MG, Gritz ER. Treating tobacco use and dependence: a clinical practice guideline. Rockville, MD: US Department of Health and Human Services, Public Health Service; 2000.

24. Lenert L, Muñoz RF, Perez JE, Bansod A. Automated e-mail messaging as a tool for improving quit rates in an internet smoking cessation intervention. J Am Med Inform Assoc 2004; 11: $235-240$.

25. Zhu SH, Stretch V, Balabanis M, Rosbrook B, Sadler G, Pierce JP. Telephone counseling for smoking cessation: effect of single-session and multiple-session interventions. J Consult Clin Psychol 1996; 64: 202-211. W 